\title{
Endocrinologia pediátrica 2011
}

\author{
Pediatric Endocrinology 2011
}

Angela Maria Spinola-Castro', Carlos Alberto Longui ${ }^{2}$, Gil Guerra-Júnior ${ }^{3}$

$\mathrm{E}^{s}$ ste número dos Arquivos Brasileiros de Endocrinologia e Metabologia que tivemos Ca oportunidade de coordenar é um suplemento especial, em Endocrinologia Pediátrica (Pediatric Endocrinology), que contou com a colaboração de vários autores nacionais e internacionais. Esses autores compartilharam conosco seus amplos conhecimentos e sua experiência, quer seja revisando alguns assuntos muito importantes na área ou produzindo trabalhos de pesquisa ainda inéditos.

Hipogonadismo, um assunto complexo especialmente em função das dificuldades para o diagnóstico, foi discutido em dois artigos, que abordaram respectivamente os aspectos clínicos e moleculares, e a experiência diagnóstica com a utilização do hormônio antiMülleriano, um importante marcador da função das células de Sertoli (1).

A cascata da diferenciação sexual se torna a cada ano mais complexa, especialmente à medida que novos genes são descritos (1). O fator esteroidogênico l (SFl) ganhou um destaque especial no artigo que discute sua importância na diferenciação sexual. Ainda nessa área, a padronização do método que possibilita avaliarmos o receptor androgênico por proteína C-reativa (PCR), em tempo real, em tecidos e sangue periférico, pode contribuir para o diagnóstico mais rápido dos casos suspeitos de insensibilidade androgênica. Confira!

A triagem neonatal, considerada ainda um assunto muito atual, especialmente pelo que representa em pediatria o diagnóstico precoce de diversas patologias (2), é rediscutida com enfoques bem diferentes, em dois artigos. O hipotireoidismo congênito é revisto depois da experiência de muitos anos, e são discutidos os ganhos, as limitações e os caminhos a serem trilhados. A hiperplasia adrenal congênita (3), que em breve deverá ser oficialmente incluída nos testes de triagem neonatal obrigatórios, também ganha um espaço com o artigo que apresenta os valores críticos de 17 hidroxiprogesterona a serem utilizados na triagem dos pacientes possivelmente afetados. Será esse um novo desafio?

Mereceu nossa atenção um fato já bem presente nos congressos pediátricos e claramente comprovamos neste número da revista que a síndrome metabólica, considerada na década anterior uma condição exclusivamente do universo adulto (4), ocupa atualmente um espaço muito importante na pediatria, especialmente porque sua prevenção hoje é responsabilidade do pediatra e deve ocorrer na infância e na adolescência. Cinco artigos discutem essa condição de diversas formas. Foram revistos os diversos critérios para diagnóstico, discutidas as questões de terminologia que trazem dificuldades algumas vezes no entendimento da patologia, mas também foram apresentados novos valores de corte para o índice de HOMA em crianças e adolescentes, com avaliação da

${ }^{1}$ Departamento de Pediatria, Setor de Endocrinologia Pediátrica, Escola Paulista de Medicina, Universidade Federal de São Paulo (Unifesp/ EPM), São Paulo, SP, Brasil 2 Departamento de Pediatria e Puericultura, Unidade de Endocrinologia Pediátrica, Irmandade da Santa Casa de Misericórdia de São Paulo (ISCMSP), São Paulo, SP, Brasil ${ }^{3}$ Departamento de Pediatria, Unidade de Endocrinologia Pediátrica, Faculdade de Ciências Médicas, Universidade Estadual de Campinas (FCM/ Unicamp), Campinas, SP, Brasil

Correspondência para: Angela Maria Spinola-Castro Rua Diogo de Faria, 307 04037-000 - São Paulo, SP, Brasil aspinola.dped@epm.br

Carlos Alberto Longui Rua Cesário Mota Junior, 61, $2^{\circ}$ andar, 01221-020 - São Paulo, SP, Brasil carloslongui@msn.com

Gil Guerra-Júnior

Departamento de Pediatria FCMUnicamp, Cidade Universitária "Zeferino Vaz",

13083-970 - Campinas, SP, Brasil gilguer@fcm.unicamp.br 
correlação desses com os fatores de risco para doença cardiovascular. As condições que predispõem à síndrome metabólica complementam de forma muito adequada a abordagem desse tema, por meio dos artigos que discutem as crianças nascidas pequenas para idade gestacional, adultos jovens com hiperplasia adrenal e os pacientes tratados por câncer na infância, todos considerados de risco para desenvolver distúrbio metabólico e com risco elevado para doença cardiovascular $(5,6)$.

Ovário policístico, patologia tradicionalmente diagnosticada na mulher adulta, mas que apresenta uma interface com o retardo de crescimento intrauterino e com obesidade, já pode ser diagnosticado clínica e laboratorialmente na adolescência, permitindo, dessa forma, minimizar as alterações ovarianas pela introdução precoce do tratamento. Confira esse artigo!

Em relação ao tema crescimento, os artigos foram bem diversificados e originais. Foi revisto o crescimento das crianças nascidas prematuras, que também podem ter restrição significativa de estatura (7), sob o aspecto clínico e também molecular, por intermédio do artigo que discute as mutações de fator de crescimento insulina-símile (IGF) como causa de retardo de crescimento pré e pós-natal. O hipopituitarismo foi abordado de uma forma diferente, mediante avaliação diagnóstica de crianças com colestase neonatal.

A estatura final dos pacientes tratados por hiperplasia adrenal, após tratamento com hormônio de crescimento e análogos para bloqueio puberal, foi objeto de um estudo retrospectivo e provavelmente será objeto de futuras discussões. Qual a sua avaliação?

$\mathrm{O}$ artigo que discute a disfunção neurossecretória do TSH em pacientes com síndrome de Down, tradicionalmente avaliados pelo risco de desenvolverem tireoidite de Hashimoto, merece atenção. Da mesma forma, também vale conferir o artigo que nos atualiza em relação ao diagnóstico e à monitorização de diabetes melito nos pacientes com fibrose cística.

O período de transição está muito bem representado na revisão dos problemas endócrinos e o seguimento das pacientes com síndrome de Turner (1). Confira!

A oncologia também tem seu espaço por meio da atualização das questões de diagnóstico e tratamento do craniofaringioma e do tumor adrenal. Ambos ainda representam um desafio sob diferentes aspectos. O craniofaringioma, tumor com importante prevalência em crianças, embora benigno, é difícil de tratar, apresenta grande frequência de recidivas e tem uma morbidade significativa. Já o tumor adrenal, apesar da grande evolução no diagnóstico laboratorial, especialmente molecular, ainda continua sendo diagnosticado tardiamente, o que compromete a sobrevida.

Acompanhando a polêmica recente quanto à segurança do uso de hormônio de crescimento $(\mathrm{GH})(8,9)$, achamos importante rediscutir esse assunto. Novos dados apresentados durante o último Congresso Europeu de Endocrinologia Pediátrica em Glasgow (2011) foram acrescentados à revisão, que temos certeza trarão uma importante contribuição nesse assunto.

Como não poderia faltar entre os temas atuais, a vitamina $\mathrm{D}$ também está presente e foi amplamente discutida em relação ao seu metabolismo e à sua importância na faixa etária pediátrica $(10)$

Com tantos temas diversos e muito bem abordados, desejamos que todos tenham uma leitura agradável e instigante.

\section{REFERÊNCIAS}

1. Maciel-Guerra AT, Guerra-Junior G. Menino ou menina? Os distúrbios da diferenciação do sexo. 2.ed. Rio de Janeiro: Rubio; 2010. p. 577.

2. Brosco JP, Seider MI, Dunn AC. Universal newborn screening and adverse medical outcomes: a historical note. Ment Retard Dev Disabil Res Rev. 2006;12(4):262-9.

3. New Ml. Ancient history of congenital adrenal hyperplasia. Endocr Dev. 2011;20:202-11.

4. Reaven GM. Banting lecture 1988. Role of insulin resistance in human disease. Diabetes. 1988;37(12):1595-607.

5. Clayton PE, Cianfarani S, Czernichow P, Johannsson G, Rapaport R, Rogol A. Management of the child born small for gestational age through to adulthood: a consensus statement of the International Societies of Pediatric Endocrinology and the Growth Hormone Research Society. J Clin Endocrinol Metab. 2007;92(3):804-10.

6. Siviero-Miachon AA, Spinola-Castro AM, Guerra-Junior G. Detection of metabolic syndrome features among childhood cancer survivors: a target to prevent disease. Vasc Health Risk Manag. 2008;4(4):825-36.

7. Wit JM, Finken MJ, Rijken M, de Zegher F. Preterm growth restraint: a paradigm that unifies intrauterine growth retardation and preterm extrauterine growth retardation and has implications for the small-for-gestational-age indication in growth hormone therapy. Pediatrics. 2006;117(4):e793-5.

8. Laron Z. Growth hormone therapy: emerging dilemmas. Pediatr Endocrinol Rev. 2011;8(4):364-73.

9. Meadows AT, Friedman DL, Neglia JP, Mertens AC, Donaldson SS, Stovall M, et al. Second neoplasms in survivors of childhood cancer: findings from the Childhood Cancer Survivor Study cohort. J Clin Oncol. 2009;27(14):2356-62.

10. van Schoor NM, Lips P. Worldwide vitamin D status. Best Pract Res Clin Endocrinol Metab. 2011;25(4):671-80. 